\title{
The Future is Bright for Competency-based Education in General Internal Medicine
}

\author{
Sharon E. Card MD, FRCPC and Narmin Kassam MD, MHPE, FRCPC, FACP
}

\section{About the Authors}

Sharon E. Card practises General Internal Medicine at the University of Saskatchewan. She is the Chair of the General Internal Medicine Specialty Committee of the Royal College of Physicians and Surgeons of Canada. Narmin Kassam practises General Internal Medicine at the University of Alberta, and is Vice-Chair of the General Internal Medicine Specialty Committee of the Royal College of Physicians and Surgeons of Canada. Both are Founders of GIM.

Correspondence may be directed to sharon.card@usask.ca

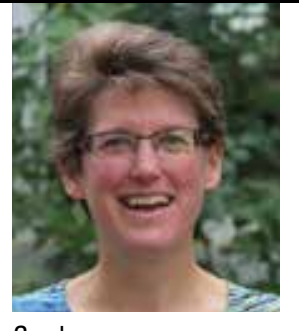

Card

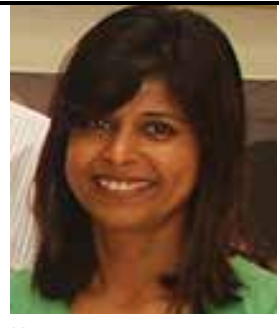

Kassam

\section{Summary}

The Royal College of Physicians and Surgeons of Canada (RCPSC) is embarking on a multi-year, transformational, educational effort entitled Competence by Design (CBD). General Internal Medicine (GIM) will be part of the 2016 cohort for Competence by Design. One of the first questions is, "What should each graduate be able to do on their first day in practice?" This paper outlines the key educational concepts behind CBD. It was presented in workshop format at the Canadian Society of Internal Medicine Meeting in September 2014. The workshop provided the authors with an opportunity to gather the perspectives and perceptions of more than 40 participants. The authors believe CBD will be an excellent format to ensure our GIM graduates are well prepared for a changing health care system.

\section{Résumé}

Le Collège royal des médecins et chirurgiens du Canada (CRMCC) s'engage dans une initiative de formation et de transformation qui s'échelonnera sur plusieurs années et qui s'intitule : La compétence par conception. Le programme de Médecine interne générale (MIG) fera partie de la cohorte 2016 touchée par l'initiative. L'une des premières questions qui sera posée est : "Qu'est-ce que chacun des diplômés devrait être en mesure de faire dès le premier jour de sa pratique? » Le présent article souligne les principaux concepts d'enseignement qui sous-tendent La compétence par conception. Il a été tout d'abord présenté dans le cadre d'un atelier lors du Congrès annuel de la Société canadienne de médecine interne en septembre 2014. Ce fut alors l'occasion pour les auteurs de recueillir les points de vue et perceptions de plus de 40 participants. Les auteurs croient que l'initiative La compétence par conception sera une excellente façon de s'assurer que les diplômés en médecine interne générale seront bien préparés à intégrer un système de soins de santé en changement. 


\section{Why is Medical Education Changing?}

The year is 1995. A recent graduate from an Internal Medicine Program establishes a practice in a community location. A patient presents themselves with critical bradycardia necessitating the insertion of a temporary pacemaker. Unfortunately, the graduate has received no training that included insertion of temporary pacemakers without the assistance of fluoroscopy. The new Internist asks for fluoroscopy and assistance, none of which is available. In the absence of fluoroscopy, the nurse gives the physician a manual to read, and offers the following comment: "Don't worry; if you go too far, ventricular tachycardia will occur."

Flash forward 20 years. Educators are considering changes to medical education aimed at ensuring each graduate from an accredited GIM residency program has the skills needed to enter unsupervised practice, as a General Internist, in a safe, effective and efficient manner no matter what the context.

\section{Overview of the Royal College of Physicians and Surgeons of Canada Competence by Design (CBD) Program}

Competence by Design (CBD) is a multi-year transformational change initiative for postgraduate medical education. ${ }^{1}$ It is designed to address societal needs and the educational needs of graduates. CBD anticipates the phases from the initiation of residency education to retirement. ${ }^{1}$ Based on a competency model of education, the aim is to ensure that everyone has the skills and competencies to safely and efficiently practise by the end of training. Although the program is designed to optimize learning by focusing on learning outcomes versus time spent, time spent will still be an essential resource in training. ${ }^{1}$ The intent is not to go to a completely time irrelevant, flexible, learning structure but instead to ensure that learning outcomes reflect what is taught and learned from programs. Learning outcomes, based on future responsibilities, are the prime driver of the CBD initiative and will ensure that graduates are able to function in the "real world".

\section{Definitions used in Competency Based Education:}

Competency - Competencies are observable abilities - they can be knowledge, skills or attitudes but, by definition, are observable and theoretically should be measurable. As cited from Frank JR et al: "Competency is an observable ability of a health professional, integrating multiple components such as knowledge, skills, values and attitudes. Since competencies are observable, they can be measured and assessed to assure their acquisition. Competencies can be assembled like building

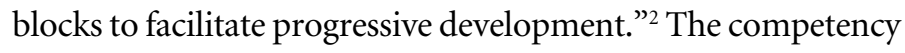

framework for the Competence by Design program will remain CanMEDs but will incorporate CanMEDs 2015. ${ }^{3}$

Entrustable Professional Activity (EPAs) - Professional Life Activities that define the discipline. As cited from ten Cate and Scheele: "EPAs are those professional activities that together constitute the mass of critical elements that operationally define a profession.... Each of these activities may be defined as a unit of work that should only be entrusted upon a competent enough professional." ${ }^{\prime}$ These may include several competencies - for example an EPA could be: "The graduate of a GIM program will be able to manage critical bradycardia in any setting". Competencies within that EPA will include medical expertise (knowledge of causes of bradycardia); communication (gaining consent from patient); collaboration (working with nurses); as well as others.

Milestones - CanMEDs 2015 introduces a new element, milestones which are observable behaviours at various stages along a continuum. A possible milestone for the pacemaker example could be: Core of the Discipline. The resident has the ability to cite the indications for the temporary pacemaker and is able to insert a temporary pacemaker under direct supervision in a fluoroscopy lab. Transition to practice: The resident is able to insert a temporary pacemaker without fluoroscopy independently. Not all competencies will need a milestone but they are intended to make it very clear to learners and their supervisors that there are areas that need to be worked on by individual learners.

\section{What are the advantages of Competence by Design for General Internal Medicine?}

We perceive this as a very exciting opportunity for General Internal Medicine to be clear about what outcomes are needed for transition to practice. As the Specialty Committee in General Internal Medicine works through the Competence by Design program, the first questions that must be answered are:

\section{- "What are the abilities that a graduate of a General Internal Medicine program needs to function independently in practice?"}

- "How can we ensure that our graduates are competent in all needed domains?"

Previous studies, conducted in the United States and Canada, have indicated that discrepancies exist between the practice patterns of internists and training. ${ }^{5-10}$ Studies have shown there are gaps in the preparation of graduates 
of Canadian training programs in several areas including in chronic care and peripartum care. ${ }^{11}$

The current Royal College of Physicians and Surgeons of Canada (RCPSC) Objectives of Training for General Internal Medicine were developed with extensive stakeholder input after reviewing the relevant Canadian literature on training needs. ${ }^{10-13}$ The key features of GIM (PGY4/5) training programs, as summarized from the RCPSC Objectives of training, ${ }^{14}$ are presented in Table 1.

\section{What is the future for Competence by Design for General Internal Medicine?}

Over the next 5 years, the Specialty Committee in General Internal Medicine will be gathering the necessary documentation for Competence by Design. By definition, this needs to be based on a robust assessment of what are the required abilities of graduates of GIM programs irrespective of the context in which they will practice. The committee will take a multi-faceted approach to gaining the information. Gathering information from workshop participants at the Canadian Society of Internal Medicine workshop, held by the authors in Calgary in October 2014, was one means to begin to gather some of this information.

Workshop participants and a variety of General Internists across Canada were asked to complete practice summaries detailing what their daily practices entail. By design, respondents were not asked to chronicle frequencies of disorders since the intent was to gather the range of scope of practice rather than define individual scopes of practice.
A summary of results is presented in Table 2. The results are a collation of 12 practice summaries from individuals who gathered data for anywhere from 1 to 7 days. The striking feature of the information gathered was that, within a 3 to 4 days sampling of only 12 General Internists, there was an incredible diversity of disorders seen, and skills performed.

At the CSIM workshop, a very dynamic discussion took place with 40 participants over 3 sessions. Participants described what they saw as the needs of graduates of General Internal Medicine programs in the future. The participants were a varied group from coast to coast in Canada approximately $32 \%$ residents; $27 \%$ involved in medical education from a scholarship or administrative perspective; $27 \%$ from large community centres and $14 \%$ from small community centres. A summary of the discussion is presented in Table 3 which summarizes areas that participants indicated should be included in the abilities of graduates from GIM programs. Participants were not asked to be all inclusive - i.e. they were not asked to identify necessarily all areas needed but rather they were asked to identify areas that needed to be included. As in the current objectives, participants were able to identify a core group of abilities required by all GIM graduates as well as the ability of each graduate to tailor their skills to their anticipated future practice location.

\section{Conclusions:}

Competence by Design promises to be a very useful tool for General Internal Medicine training. It will provide a template for training design that is tailored to the future employment

Table 1. Key Features of General Internal Medicine Training Programs as summarized from the Royal College of Physicians and Surgeons GIM Objectives of Training. 1

\section{At the end of GIM Training the graduate} will be able to manage/perform:

1. Common \& Emergency Internal Medicine Conditions

2. Internal Medicine conditions before, during and after pregnancy.

3. Multi-system disease.

4. Perioperative Care.

5. Risk Reduction

6. Procedures:
a. Ambulatory Blood Pressure monitoring
b. Holter monitoring
c. Exercise Stress Testing
d. Invasive and non-invasive ventilation

\section{At the end of GIM Training the graduate} will be able to:

Develop a practice that is:

- Adapted to societal needs.

- Maintains generalist principles, but may be quite different than others to meet needs of their community.

- Able to adapt over time.

- Respects limits.

- Incorporates effective inter and intra-professional collaboration including excellence in transitions in care.

2. Improve population health outcomes through:

- Patient Safety Initiatives.

- Preventive Care.

- Health Care Delivery Initiatives.

- Advocacy for vulnerable populations.

- Education (patients, students, and/or colleagues) 
Table 2. Practice Summaries - Summary of Disorders Seen and Skills Used by 12 General Internists in less than a week.

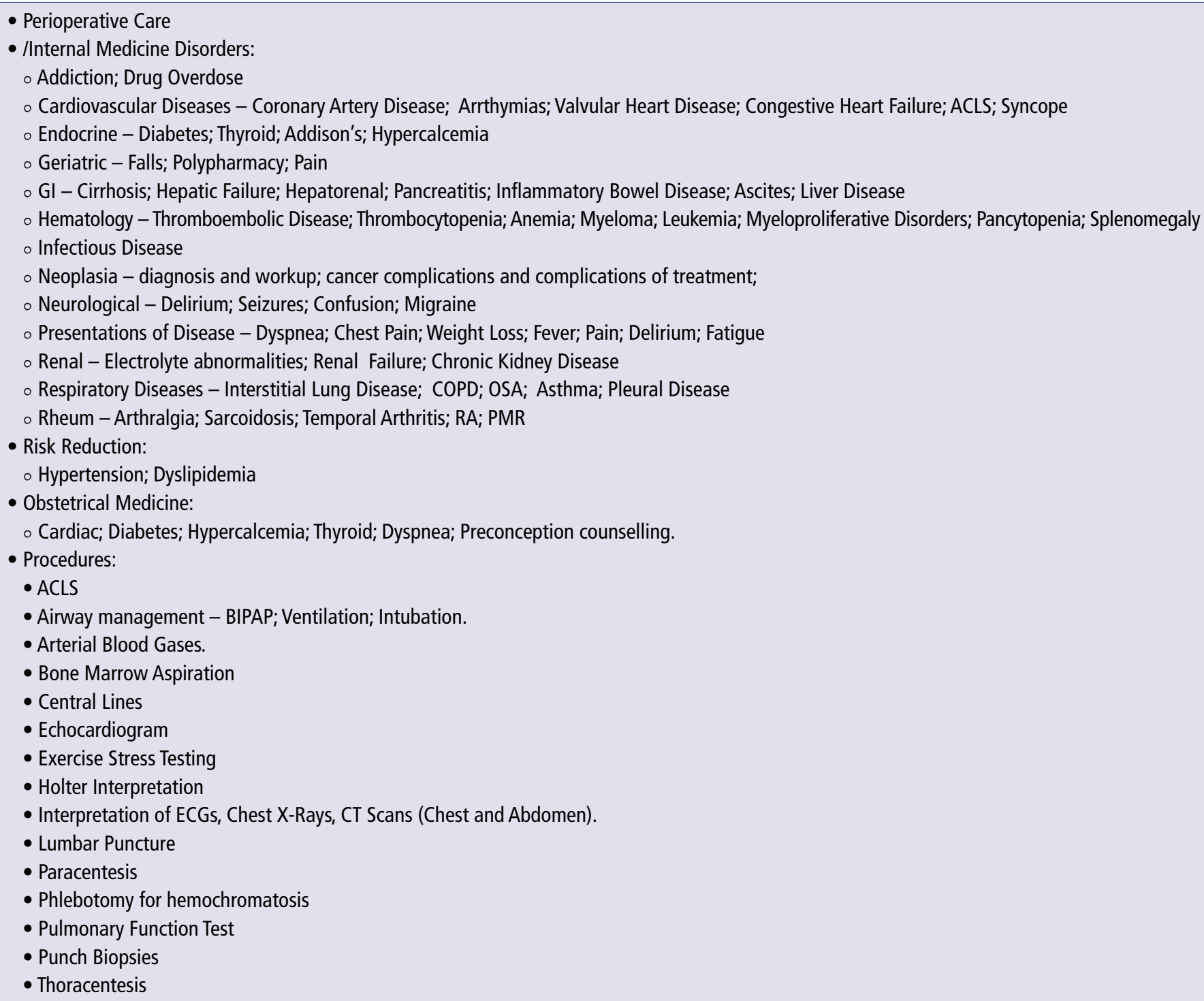

needs of General Internal Medicine practitioners with varied approaches to practice across the country. Identifying the desired abilities of graduates from GIM programs, from the perspectives of many, will be the first step in the process. It will be very useful for the committee to hear from a wide range of GIM practitioners across the country to ensure that the abilities are truly defined. Please let us know your thoughts!

\section{Acknowledgements:}

We are very grateful to the participants in sharing their wisdom on the practice of General Internal Medicine across Canada. The practice audit summaries were part of another study that was considered exempt by the University of Saskatchewan Behavioral Ethics Review board as it is considered program evaluation.

\section{References:}

1. Royal College Website - Competence by Design - Accessed March 16, 2015 http://www.royalcollege.ca/portal/page/portal/rc/resources/cbme.

2. Frank JR, Snell LS, Ten Cate O et al. Competency-based medical education: theory to practice. Med Teach 2010; 32: 638- 645.

3. Royal College Website - CanMEDs 2015 - Accessed March 16, 2015 http://www.royalcollege.ca/portal/page/portal/rc/canmeds/canmeds2015.

4. Ten Cate $\mathrm{O}$ and Scheele F. Viewpoint: Competency-Based Postgraduate Training. Can We Bridge the Gap Between Theory and Clinical Practice? Acad. Med 2007; 82: 542-547.

5. Mandel JH, Rich EC, Luxenberg MG, Spilane MT, Kern DC, Parrino TA. Preparation for practice in internal medicine. A study of ten years of residency graduates. Arch Int Med 1988; 148: 853 - 86.

6. Baker MZ and Scofield RH. Educational needs of internal medicine residency graduates: general internist versus subspecialists. Medical Education 1988; 32: $527-532$. 
Table 3 - What should a GIM graduate be able to do at the completion of training? Perspectives of CSIM Workshop Participants.

\section{Medical expert - At the time of graduation from a GIM residency} will be able to:

- Independently manage:

- Perioperative patients

- Complex, multisystem patients

- Chronic Care

- Acute internal medicine problems.

- Preventive care

- Have the skills to:

- Adapt knowledge to specific context - competent in a multitude of settings

- Deal with uncertainty and areas where there is little or no evidence

- Approach issues with common sense

- Generate a problem list

- Apply good clinical skills at bedside

- Approach undifferentiated problems

Communicator - At the time of graduation from a GIM residency will be able to:

- Understand reason for referral from both referring individual and perspective of the patient.

- Able to communicate with:

- Patient (based on education level) and elicit why patient thinks they are referred to you.

- Referring physician or others (nurse practitioners, etc.)

- Provide and seek practical information

- Demonstrate proper documentation
Collaborator - At the time of graduation from a GIM residency will be able to:

- Understand consultant role

- Provide integrated care inclusive of all members of the team.

- Manage multi-disciplinary teams

Manager - At the time of graduation from a GIM residency

will be able to:

- Demonstrate excellent time management including efficiency, ability to meet timelines and still gather relevant information.

- Demonstrate:

- Triaging skills - discriminate what's urgent.

- Adapt to context

- Ability to manage an office.

- Resource stewardship

- Leadership roles at hospital or societal levels

Advocate - At the time of graduation from a GIM residency

will be able to:

- Promote, recognize and respect patient autonomy

- Motivate patients to be compliant

- Adapt to the community they serve

- Meet the needs of the community

Professional - At the time of graduation from a GIM residency will be able to:

- Demonstrate professional self-assessment - understand own knowledge gaps, and impact of fatigue on one's performance.

- Deal with bad outcomes/actions

- Know limitations and when to consult

Scholar - At the time of graduation from a GIM residency

will be able to:

- Demonstrate curiosity

- Know and apply evidence to decision making

- Demonstrate principles of lifelong learning - knows the resources, how to make learning plans and reflects

- Demonstrate ability to train and educate others
7. Miller DB. Procedural Skills: A Survey of General Internists in British Columbia. Annals RCPSC 1992; 25(6): 355 - 7.

8. Wiest FC, Ferris TG, Gokhale M, et al. Preparedness of internal medicine and family practice residents for treating common conditions. JAMA. 2002; 288: $2609-2614$.

9. Blumenthal D, Gokhale M, Campbell EG, Weissman JS. Preparedness for clinical practice: reports of graduating residents at academic health centers. JAMA. 2001; 286: 1027 - 1034.

10. Shamekh F and Snell L. Are Internal Medicine Residents Prepared for Ambulatory Practice? Clin \& Invest Med; 1999; 22 (4 supp): S29. Abstract \# 250.

11. Card SE, Snell L, O’Brien B. Are Canadian General Internal Medicine training program graduates well prepared for their future careers? BMC Medical Education 2006; 6:56.
12. Soparkar GR and Card SE. Technical Skills During Residency and in Practice: A Survey of Specialists in Internal Medicine in Saskatchewan. Annals RCPSC 1999; 32(5): 296 - 301.

13. Card SE, Pausjenssen AM, Ottenbreit RC. Determining specific competencies for General Internal Medicine Residents (PGY 4 and PGY 5). What are they and are programs currently teaching them? A survey of practicing Canadian General Internists. BMC Research Notes 2011, 4:480

14. http://www.royalcollege.ca/portal/page/portal/rc/credentials General Internal Medicine Objectives of Training - under Information by Discipline; Subspecialty; General Internal Medicine. Accessed January 8th, 2015. 